\title{
Golden Plovers
}

\section{By HENRY SAVARD, Carvel, Alberta}

On May 13, while driving west some fifteen miles from Edmonton, we were met by a sight which I for one will not soon forget. As we rounded a bend in the highway we saw a great flock of birds, easily over three hundred in numbers. They were spread out over a pastured field right next to the highway. The point that stirred in us the greatest interest however, was the fact that not one of us (six in all) had ever before seen birds such as these. My uncle, who was driving the car, immediately pulled over to the side and stopped so that we could, if possible, identify them. Although we were then within about twenty-five yards of the nearest of the flock, the birds seemed unconcerned and many even advanced much closer, as if curious to see just what type of beings we were. How I regretted not having brought my field guide with me!

From their actions and appearance, we decided that the birds belonged either to the plover or sandpiper family. Each member of the flock seemed constantly on the move, running here and there as though in search of insects. Many of them would run toward us and then stand facing us with black breasts showing prominently. We noted also, a broad white stripe which extended over and behind the eye continuing down the side of the neck and breast. The back appeared, from the car, a dark brown.

Once when a car passed by on the highway, they all took to the air in a great mass. So close did they fly to each other, that had a shot been fired into them, I'm sure the result would have been disastrous. Circling briefly they returned, and once again alighted near the highway.

Quite sure that we could now identify them later, we drove on. It was getting late and we still had twenty miles to travel before reaching home. How I wished that I could have obtained a specimen to mount or at least a picture as it seemed unlikely I would ever see any of these birds again! I was in for a surprise however, for as we turned into my uncle's farm we spotted a single pair just ahead, running along on the short-cropped pasture grass.

When we arrived at the house we took a .22 rifle and hurried back to the spot. To my relief the birds were still there and my uncle was able to shoot one. Later we identified them as golden plovers, called so probably because of the beautiful yellow spotting of the back and wings. My mounted specimen now occupies a place on a window ledge in our home.

Most references classify the golden plover as a rare bird. In the spring they migrate from South America and pass chiefly through the Mississippi valley to their breeding grounds in the Arctic. It would seem that in this instance, they were for some reason far west of their usual migration route. Because of this, I feel we were especially fortunate to have encountered them.

\section{A Word of Appreciation}

\section{By A. C. BUDD}

I would like to express my appreciation to Mrs. W. K. Cruickshank for the inspired articles which for so long a time she has been contributing to the Blue Jay. I feel that she should be honoured as an outstanding naturalist and conservationist. These articles are so splendidly written, the language is perfect, the quotations are apt and fitting, the natural history facts are all correct and still the articles are easily readable. Most articles, where the facts are accurate, are dull and uninteresting but Mrs. Cruickshank writes a story that one cannot help reading. Here is invariably the first article I turn to in each new issue and the one that I re-read most often.

One can easily visualize the scenes she describes - the various adventures of Gram, Judy and Fogarty the dog, and also appreciate the thoughts expressed. Personally I think these kinds of articles do far more to encourage nature appreciation than scientific articles, of interest only to those who are interested in the particular subject. 